\title{
Produção de mudas nativas, frutíferas e de hortaliças no semiárido: $O$ caso do Viveiro de Mudas Cílios da Terra Assentamento Estrela do Norte-MG
}

\author{
Deyvison Lopes de Siqueira ${ }^{1}$ https://orcid.org/0000-0003-0393-1292 \\ Wesley José Cardoso ${ }^{2}$ https://orcid.org/0000-0003-1861-0002
}

Gustavo Henrique Cepolini Ferreira ${ }^{3}$ https://orcid.org/0000-0003-1010-501X

\footnotetext{
${ }^{1}$ Mestrando em Geografia - Universidade Estadual de Montes Claros. E-mail: deyvisonsiqueira@ yahoo.com.br

${ }^{2}$ Engenheiro Agronômo - Universidade Federal de Minas Gerais. Coordenador Técnico do Viveiro - MST. E-mail: wesleyjosecardoso@hotmail.com

3 Professor do Departamento de Geociências e PPGEO - Universidade Estadual de Montes Claros. E-mail: gustavo.cepolini@unimontes.br
}

\section{Resumo}

O viveiro de mudas Cílios da Terra faz parte de um projeto do Movimento dos Trabalhadores Rurais Sem Terra (MST), cujo objetivo principal é promover a recuperação de áreas degradadas de assentamentos do MST e fortalecer as atividades produtivas. Este trabalho tem como objetivo apresentar a experiência de produção de mudas nativas, frutíferas e de hortaliças do viveiro Cílios da Terra na região Norte de Minas Gerais. A metodologia baseia-se na coleta de informações por meio do trabalho de campo e entrevista com o coordenador do viveiro, entre outros extensionistas. $\mathrm{O}$ resultado desse relato aponta que a produção de mudas do viveiro tem promovido ações de trabalho coletivo, desenvolvendo ações de fortalecimento da agroecologia nas áreas de assentamentos da região, principalmente através das experiências de produção por meio do sistema agroflorestal.

Palavras-chave: Cílios da Terra. Produção de mudas. Sistemas agroflorestais.

A experiência do viveiro de mudas Cílios da Terra é um projeto que iniciou através da parceria entre o Movimento dos Trabalhares Rurais Sem Terra - MST e o governo do estado de Minas Gerais para produção, plantio e distribuição de mudas que subsidiem o reflorestamento de áreas degradadas, articulado ao projeto Recuperando Áreas Degradadas em Assentamentos da Reforma Agrária (RADAR) inseridas no contexto do Projeto Plantando Futuro da Companhia de Desenvolvimento Econômico de Minas Gerais (CODEMGE), também vinculados ao projeto "Implantação de Sistemas Agroflorestais em áreas de reforma agrária como estratégia de recuperação de áreas degradadas" com financiamento da 
Companhia Energética de Minas Gerais (CEMIG). Assim, o viveiro Cílios da Terra, instalado no Assentamento Estrela do Norte, município de Montes Claros-MG, é uma das oito experiências de viveiros de mudas do MST em áreas de Reforma Agrária no estado de Minas Gerais. Atualmente, o viveiro vem produzindo mudas de árvores nativas e frutíferas (pequi, umbu, baru, ipês, jacarandás, tamboril, cajá, pinha, jaca, graviola, jabuticaba, abacate, goiaba, araçá, dentre outras) e as mudas de hortaliças (alface, couve, tomate, pimentão, brócolis, pimentas, couve, jiló, berinjela). Essa produção de mudas de nativas e frutíferas tem o objetivo de recuperar áreas degradadas dos assentamentos da região norte de Minas Gerais por meio de práticas agroflorestais, as quais visam a produção de alimentos saudáveis, recuperação de nascentes e recuperação da biodiversidade do cerrado.

Para além das supracitadas, existe também a produção de mudas de hortaliças que atualmente visa atender as demandas das famílias camponesas dos assentamentos (Darcy Ribeiro, São Francisco e Estrela do Norte), bem como de acampamentos onde existem atuação ativa do MST (João Pedro Teixeira, Eloy Ferreira e Professor Mazzan nas respectivas cidades, Olhos d'agua, Engenheiro Navarro e Bocaiuva) e as demais comunidades situadas no entorno do viveiro. Essa produção de mudas de hortaliças destinadas às famílias dos assentamentos e acampamentos, tem o objetivo de fortalecer a produção garantindo segurança alimentar e geração de renda através da comercialização da produção em feiras livres locais e também através da cooperativa Camponesa Veredas da Terra. Essa cooperativa possibilita um planejamento produtivo para acessar os mercados institucionais, principalmente na cidade de Montes Claros, onde estão concentradas várias escolas estaduais e municipais.

Ao se tratar de meio ambiente, o viveiro Cílios da Terra tem um papel fundamental e estratégico na região Norte de Minas, pois essa região vem sofrendo nos últimos anos com a degradação de áreas do cerrado, irregularidade das chuvas, atuação de empresas de exploração de minério e plantios de monoculturas. Assim, ressalta-se a importância do cultivo e a comercialização de mudas direcionadas, principalmente para órgãos públicos, empresas privadas, entidades não governamentais e a sociedade civil, que realizam ações de plantio e recuperação de áreas degradadas na região.

Nesse sentido, o viveiro vem promovendo atividades em parceria com a Secretaria de Meio Ambiente de Montes Claros com o fornecimento de mudas e, também, com o Instituto de Ciências Agrárias da Universidade Federal de Minas Gerais realizando visitas técnicas com estudantes dos cursos de Engenharia Agronomica e Engenharia Florestal o que promove o diálogo com a sociedade. 


\section{Produção de mudas nativas, frutíferas e de hortaliças no semiárido}

Deyvison Lopes de Siqueira; Wesley José Cardoso; Gustavo Henrique Cepolini Ferreira

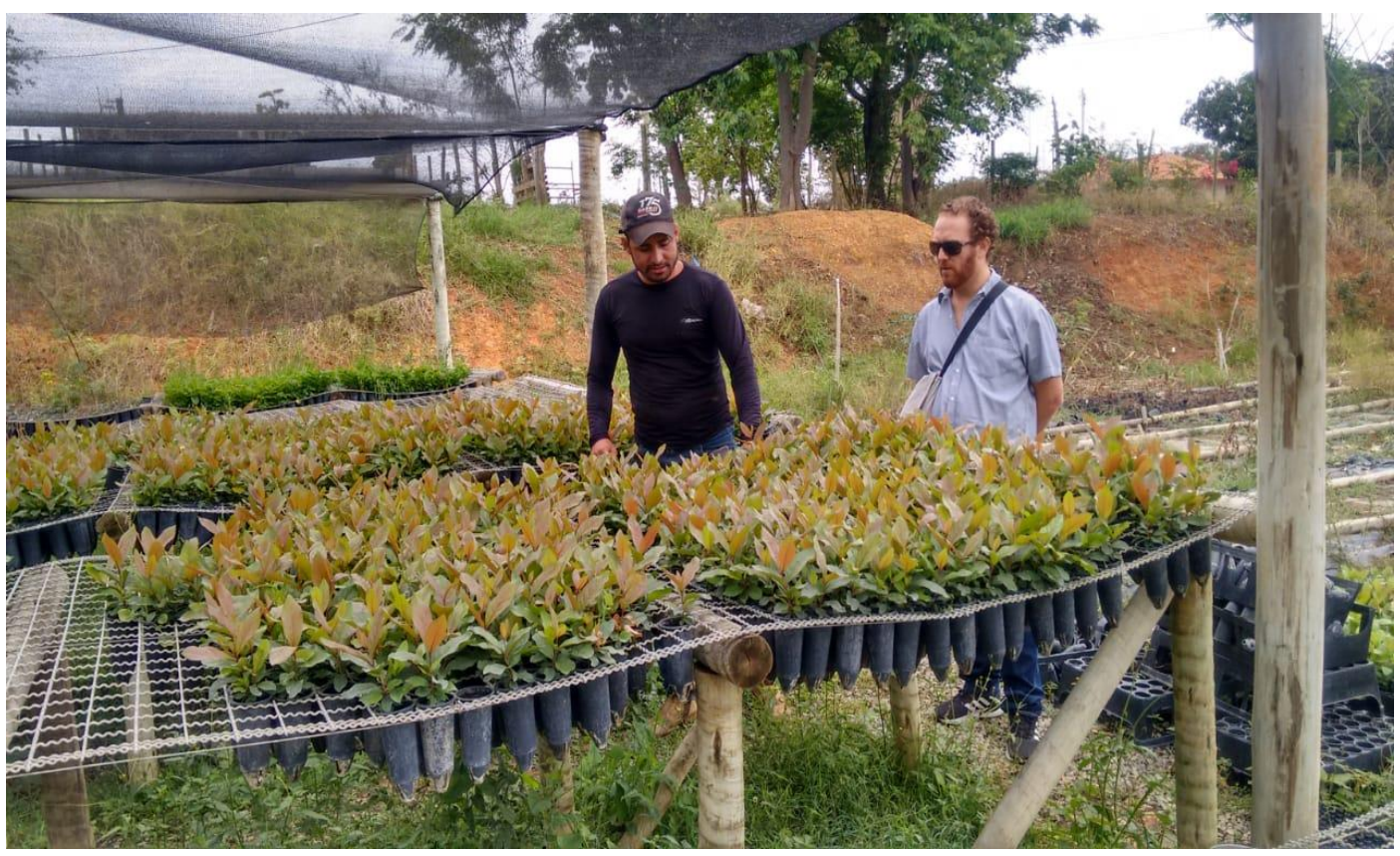

Figura 1: Canteiro de mudas do viveiro Cílios da Terra - Assentamento Estrela do Norte. Fonte: Deyvison Siqueira, 2019.

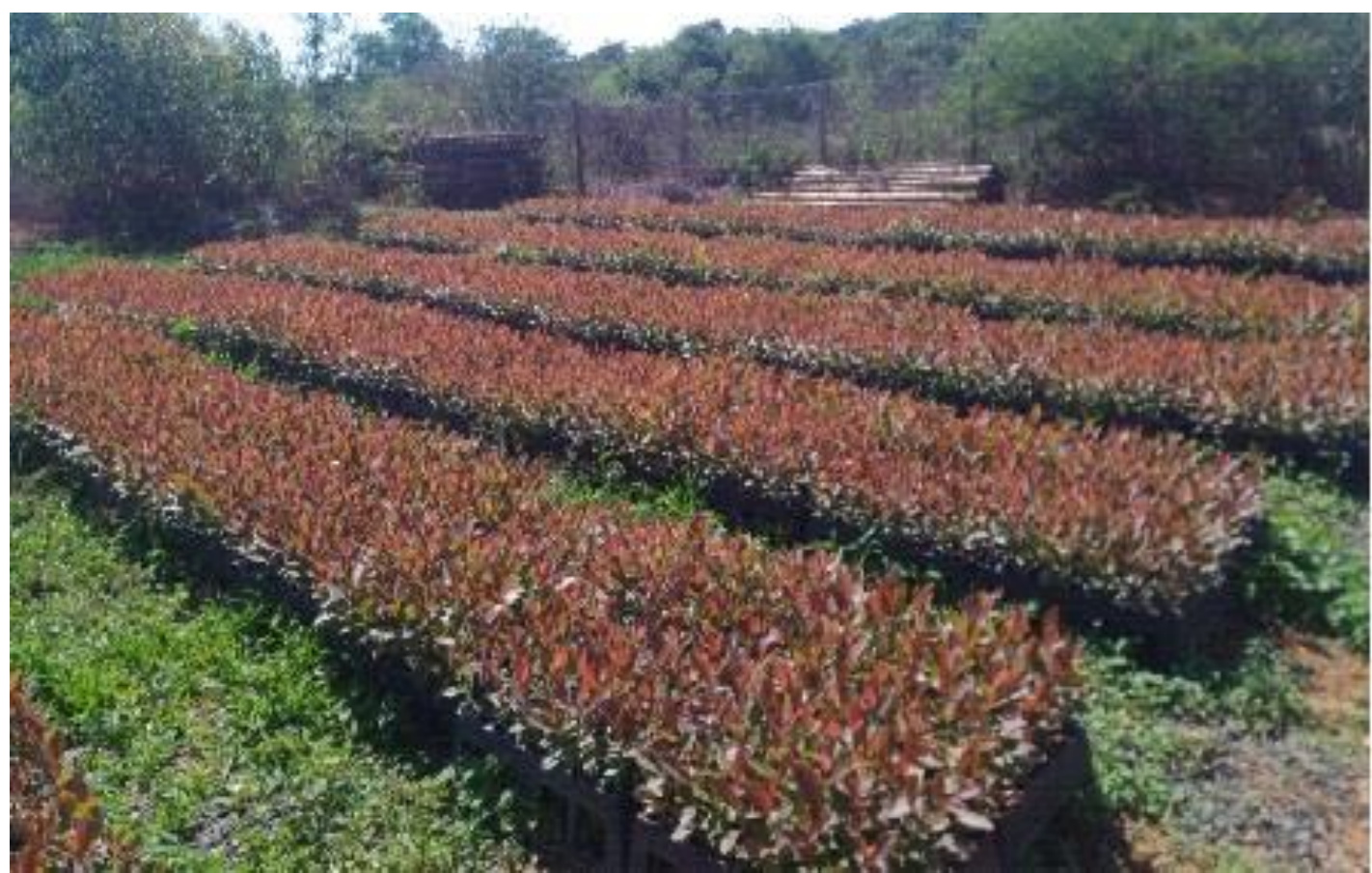

FIGURA 2: Mudas de Araça. Fonte: Wesley Cardoso, 2019. 
Produção de mudas nativas, frutíferas e de hortaliças no semiárido

Deyvison Lopes de Siqueira; Wesley José Cardoso; Gustavo Henrique Cepolini Ferreira

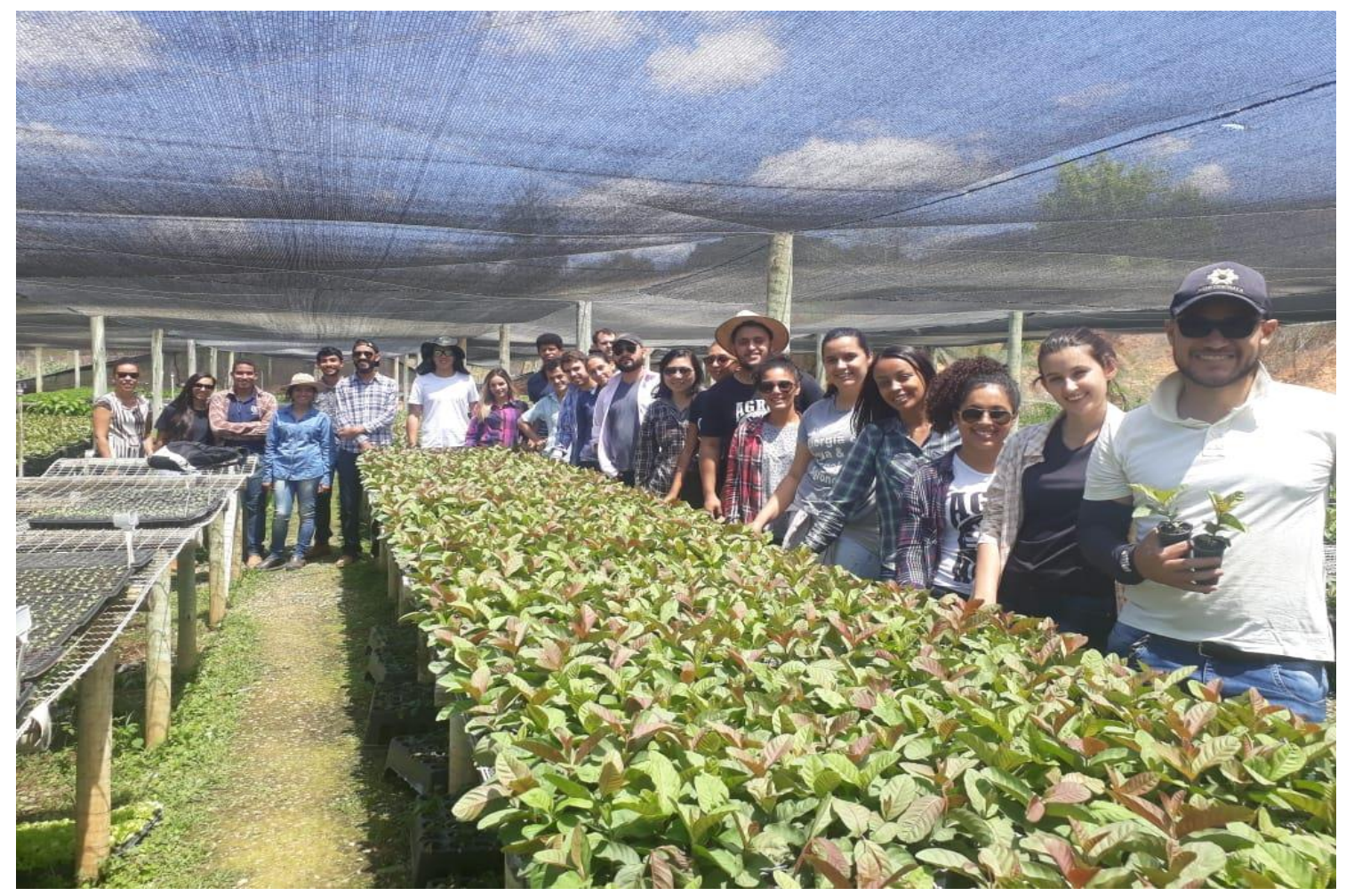

Figura 3: Visita técnica dos alunos do curso de Agronomia do ICA/UFMG.

Fonte: Wesley Cardoso, 2019.

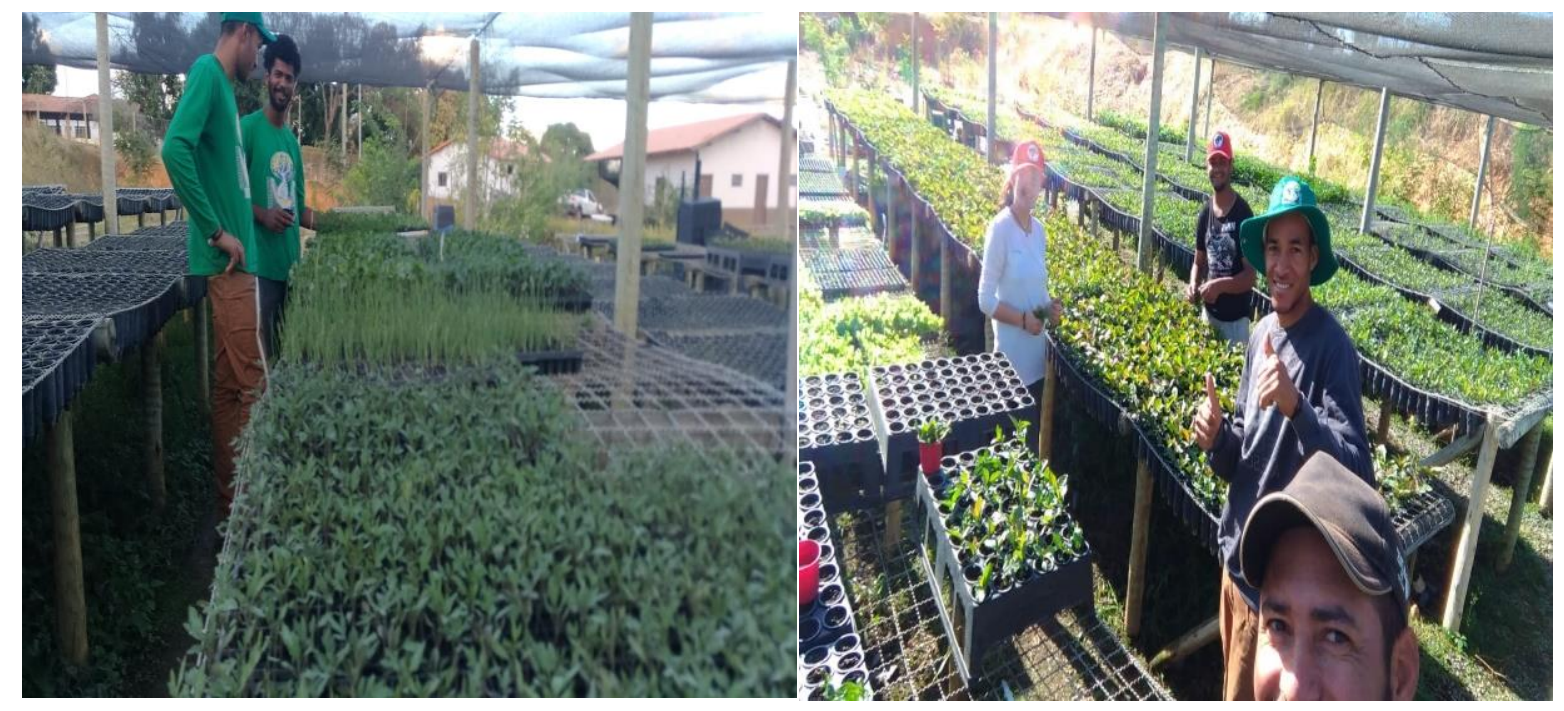

Figuras 4 e 5: Equipe de trabalho do viveiro Cílios da Terra. Fonte: Wesley Cardoso, 2019. 
Deyvison Lopes de Siqueira; Wesley José Cardoso; Gustavo Henrique Cepolini Ferreira

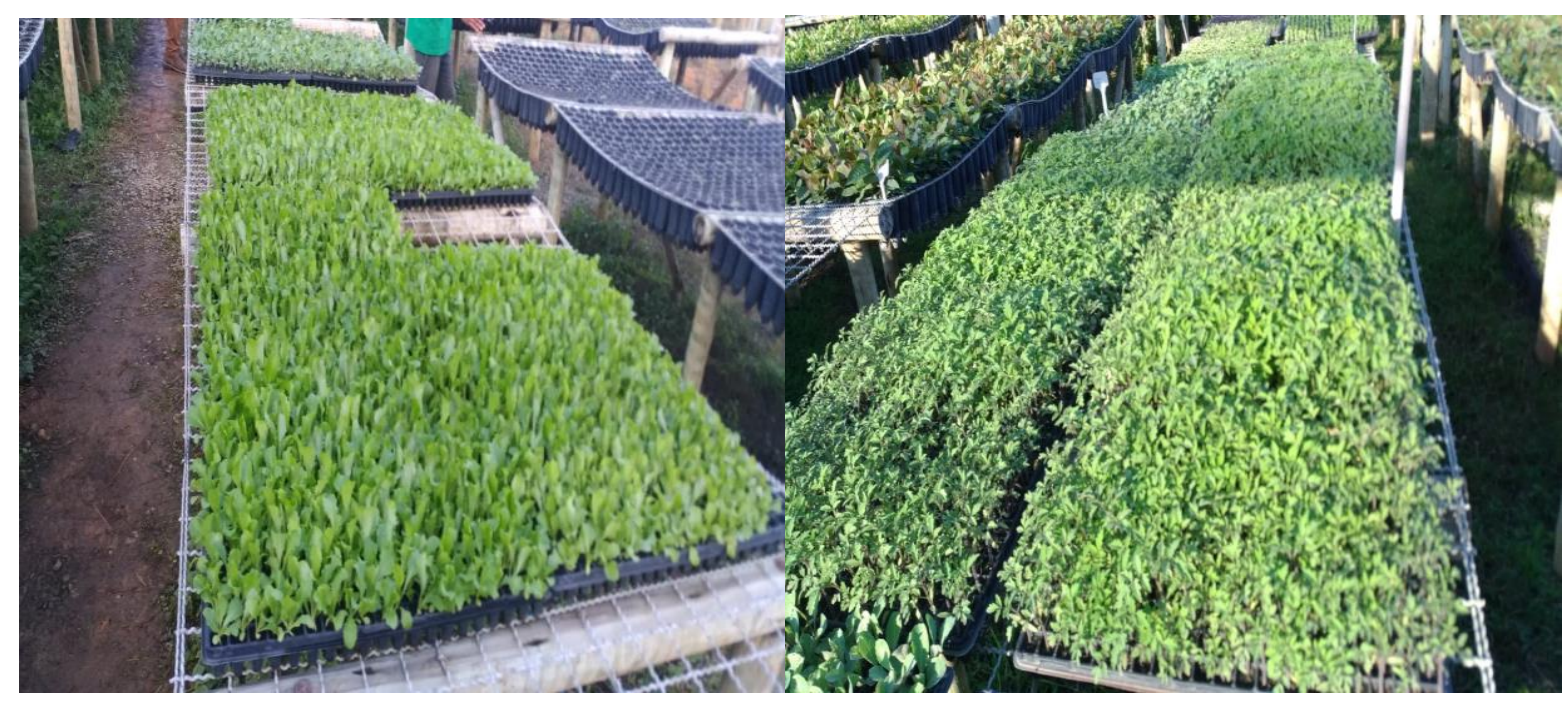

Figuras 6 e 7: Produção de mudas de hortaliças. Fonte: Wesley Cardoso, 2019. 